so much pretty blue smoke and mirrors. ...

And let's have no more kneeling for good reasons, dropping God's name

like a cast iron doorstop,

forcing Him into the shape of a tree,

say, which would much rather go on treeing.

Let's sit down at the table, and eat.

Pass the chicken, sauteed with onions,

pass the broccoli, its green aroma

curling from the plate. Pass the boiled

red potatoes that slice open

with warm sighs. Pass the spring

water and the wine, the butter and the pepper.

Quiet the children according to their

needs. Quiet the radio and TV, all appliances

of confusion, of $I$ will never solve these

too painful and unending sorrows. Quiet

your opposite, as well as he or she

may be comforted. Quiet, quiet your own famished

heart. Let us fill ourselves in silence.

\title{
Prayer to Wasp on the Occasion of Its Execution
}

You entered my face

like a whore's nails,

blew the skin out

red and dangerous

as a balloon

filled with gas.

Twelve years old,

I lurched

home, new pennies 
slid from my jeans

ticking the side-

walk. Friends

dropped their mitts

and stared.

Only creature

I still kill,

prying your stucco

nests from rafters,

hearing the sound

of your body

breaking underfoot-

brittle, crushed

paper flower-

forgive this un-

redeemable

vengeance. Today

your descendant

enters through a hole

in the screen,

slow and fumbling,

falls off

the sill to my

desk. I will send

him back to God

using the sonnets

of Frederick

Tuckerman, an old

favorite, sad

lush lines to a dead

wife. Please convey

my regrets

to the Absent One-

I have not loved

all, or enough

without words,

lies or poisoned

hesitations.

Have mercy on me. 